\title{
Verbal discrimination learning as a, function of experimental frequency
}

\author{
JOE BERKOWITZ, Department of Psychology, University of \\ Virginia, Charlottesville, Va. 22903
}

After learning a 16-pair verbal discrimination (VD) list to criterion, Ss were transferred to a 24-pair list. The transfer list was composed of three sublists of eight pairs each; one sublist was formed by pairing correct items from the first list, a second sublist was formed by pairing incorrect items from the first list, and the third sublist was composed of pairs of new items. Performance on the transfer list was found to be highest for the new pairs and lowest for the pairs comprised of previously correct items. The results were interpreted as providing strong support for the frequency theory of verbal discrimination learning.

In a verbal discrimination (VD) task, $S$ is presented with pairs of verbal items and must learn which member of each pair is correct, as arbitrarily designated by $\mathrm{E}$. The frequency theory of verbal discrimination (Underwood, Jesse \& Ekstrand, 1964; Ekstrand, Wallace \& Underwood, 1966) states that the basis for the discrimination of a correct from an incorrect item is a difference in frequency of occurrence which builds up between members of a given pair during the course of acquisition. ${ }^{2}$ This differential build-up is characteristic of the VD procedure, wherein the correct item is repeated by $S$ in the form of representational, pronunciation, and rehearsal responses, more often than the incorrect item. Since it is these responses which result in the addition of frequency units to members of the pair, the correct member of each pair comes to have a greater frequency associated with it than does the incorrect member. The S, according to Ekstrand et al (1966), chooses that member of the pair to which there has been the greatest frequency build-up; that is, he gives that item with which he has responded, either overtly or covertly, more often.

The present investigation was designed as a test of the frequency theory. According to the theory, a consequence of VD learning should be the accrual of higher cumulative frequencies for the correct items than for the incorrect items. If these correct items are now paired, and the incorrect items are paired, a new VD list is generated consisting of high frequency and low frequency pairs. If an important factor in making the discrimination between members of a given pair is the relative rather than absolute difference in frequencies, then one might expect the frequency units which accrue during the learning of this new list to be of greater benefit to low frequency pairs. According to Ekstrand et al (1966) "... an extra frequency unit added to a member of a high frequency pair should not be 'worth as much' in terms of cue value as a frequency unit added to a member of a low frequency pair" (p. 576). In a similar fashion, an extra frequency unit added to a member of a new pair, the items of which were not in the first VD list and therefore possess no experimentally-induced frequency, should be "worth the most." Thus, in a VD list consisting of high frequency pairs, low frequency pairs and new pairs, the frequency theory would predict acquisition to be fastest for the new pairs and slowest for the high frequency pairs.

Design and Subjects

\section{METHOD}

The Ss were 30 male undergraduates enrolled at the
University of Virginia. All Ss learned two VD lists with the second list being the locus of the experimental manipulation. The second list was comprised of three sublists which were formed as follows: in Sublist C, correct items from the first list were paired; in Sublist I, incorrect items from the first list were paired; in Sublist N, new items were paired. To control for any item effects in first-list learning which could bias performance on the second list, two forms of the first list were employed; the member of a given pair which was correct for half the Ss was incorrect for the other half. Thus, items which formed Sublist C for half the Ss constituted Sublist I for the remaining Ss.

Lists

The stimuli were 48 common English words of AA frequency in Thorndike-Lorge (1944). Thirty-two words were paired to form the 16-pair first list. The second list was formed by pairing the 16 correct words from the first list, pairing the 16 incorrect words from the first list, and pairing the 16 new words remaining from the original 48 . All pairs were generated randomly from the appropriate stimuli with the restriction that members of a given pair begin with different letters.

\section{Procedure}

For both lists, each pair was projected by a Kodak Carousel slide projector on a translucent screen for $2 \mathrm{sec}$ while $\mathrm{S}$ made his response, and then the pair was presented again for $2 \mathrm{sec}$ with the correct member underscored. The intertrial interval was $10 \mathrm{sec}$. Within a given list, four different orders of pairs were used. For both lists, the correct member of each pair appeared half the time on the right and half on the left. Within each trial, half of the correct words appeared on the right and half on the left.

Learning of the first list was carried to a criterion of $15 / 16$ ths correct plus five additional trials. The overlearning procedure was employed to create fairly large differences in frequency between the correct and incorrect items. When Ss reached criterion on the first list, they were instructed about the second list, in part, as follows: "This list is composed of 24 pairs of words. Some of these words were used in the previous list, some are new words. No pair of words is the same as in the first list. Previously correct words may or may not be

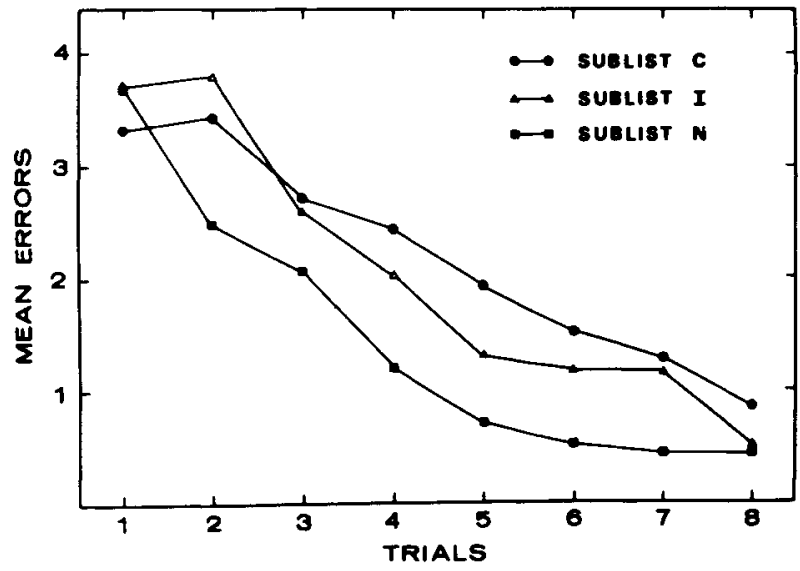

Fig. 1. Mean numbers of errors for each of the three conditions in the transfer list as a function of trials. 
corret in this second list." The transfer list was presented for eight trials.

\section{RESULTS AND DISCUSSION}

The mean number of errors as a function of trials for each of the three conditions in the transfer list are presented in Fig. 1. An analysis of variance was performed on the error scores with sublists and trials as within-Ss variables and form of first list as between-Ss variable. The analysis yielded a highly significant main effect of sublists $(F=25.16$, df $=2 / 56$, $p<.001)$. In addition, a significant Sublists by Trials interaction was obtained $(\mathrm{F}=2.81, \mathrm{df}=14 / 392, \mathrm{p}<.01)$, indicating that performance on the three sublists began at approximately the same level, but improved at different rates. To determine if the predicted order of performance was obtained, a Tukey (a) test (Winer, 1962) was run. The results showed that the differences between Sublist $N$ and Sublist I, and between Sublist I and Sublist C, were significant at the .01 level. Thus, performance on the transfer list was highest for the new pairs and lowest for the high frequency pairs. Neither the main effect nor any interactions involving form of first list was a significant source of variance (all p's $>.10$ ).

The results substantiate the predictions made by the frequency theory. It appears that Ss, in learning a VD list, are responding by choosing the more frequently occurring member of a given pair. Moreover, the results suggest that the cue for the discrimination is the relative rather than the absolute difference in frequency. A given increment in frequency, therefore, is of greater value the lower the absolute frequency level.

\section{REFERENCES}

EKSTRAND, B. R., WALlace, W. P., \& UNDERWOOD, B. J. A frequency theory of verbal-discrimination learning. Psychological Review, 1966, 556-578.

THORNDIKE, E. L., \& LORGE, I. The teacher's wordbook of 30,000 words. New York: Teachers College, Columbia University, 1944.

UNDERWOOD, B. J., JESSE, F., \& EKSTRAND, B. R. Knowledge of rights and wrongs in verbal-discrimination learning. Journal of Verbal Learning and Verbal Behavior, 1964, 3, 183-186.

WINER, B. J. Statistical principles in experimental design. New York: McGraw-Hill, 1962.

\section{NOTES}

1. This research was supported in part by a grant from the National Institute of Mental Health (MH-14059-01) to Eugene A. Lovelace. The author expresses his appreciation to Eugene A. Lovelace for his helpful suggestions.

2. Frequency, as referred to by Ekstrand et al (1966) is in terms of context-bound, experimentally-induced frequency. This is the sense in which it will be used in the present paper. 